\title{
Factors affecting the practicality of solid-phase microextraction VOC analysis of artworks featuring polymeric materials in open environments.
}

\author{
M. Kearney 1 , J.H. Townsend'2, I.P. Parkin³, M. Hidalgo4, K. Curran'1. \\ IUCL Institute of Sustainable Heritage, Central House, 14 Upper Woburn Place, \\ London, WCIH ONN, UK \\ ${ }^{2}$ Conservation Department, Tate, London, UK \\ 3UCL MAPS Faculty Office, 1st Floor, South Wing, Gower Street. \\ ${ }^{4}$ Arkema, Paris, France \\ Keywords: polymer, plastic, VOC, SPME, GCMS
}

\begin{abstract}
-
Currently there is no proven method for in-situ monitoring of the decay progression of objects featuring polymeric materials. One potential method which is gaining traction, is the analysis of volatile organic compounds (VOC) via solid phase microextraction gas chromatography mass spectrometry (SPME-GC/MS). Few studies have focused on repeated, long-term monitoring of objects in open heritage environments via SPME-GC/MS. Specifically, the combined effects on methodological performance of the fibre exposure time in conjunction with the effects of variable environmental conditions over that period and fibre location with relation to the object have yet to be investigated. In order to study these effects, we tracked four key VOCs emitted from Naum Gabo's constructivist sculpture Construction in Space 'Two Cones' (Tate) by repeated SPME-GC/MS analysis. Five fibres in total were placed around the object and within its storage room. Two separate experimental campaigns were carried out, one exposing the fibres to the object for 1 Day, the other for 7 days. Our results show that an exposure time of 7 Days led to a lower relative standard deviation than for a 1 Day exposure time for each of the four VOCs. However, our results also show that the performance of individual fibres, at their specific locations, was better with an exposure time of 1 Day. Furthermore, we highlight the comparability of the background VOC profile to a location within the object's storage crate.
\end{abstract}


The implications of our research are two-fold - firstly, when monitoring in an open environment, a shorter exposure time leads to more repeatable analysis over long time periods, however, it is at the expense of the ability to calculate concentrations as the fibre has not yet reached equilibrium. Secondly, background and object VOC profiles can be difficult to distinguish unless the fibre is in immediate vicinity of the point of interest. 


\section{Introduction}

The presence of art objects within museum collections which are either entirely or partly manufactured with polymers has become an issue for their host institutions. This is due to the base polymer often displaying signs of deterioration, even within ideal museum conditions, at reasonably short time periods after acquisition (typically 5-25 years)[1]. While much research has been carried out over the past 25 years, as recently as 2014 our understanding of their stability has been described as "rudimentary" [2]. Strlič and Curran [3] have also noted the need to further study the decay of polymers outside of their industrial applications, with specific emphasis on their use within the art and design industries. At a national level, the United Kingdom's National Heritage Science Strategy Report of 2009 has also highlighted the need for improved monitoring of polymer artworks [4].

Despite the identification of this need, currently, there is no method developed for systematic monitoring of polymer artworks within a museum collection.

One methodology identified as having the potential to monitor polymer objects non-destructively and non-invasively within museum environments is via the emission of volatile organic compounds (VOCs) from the surface of the object [5]. The most well-noted example, within a heritage context, of Vocs emitted from polymer objects is known as the 'vinegar syndrome' - the release of acetic acid from cellulose acetate (CA) as it deteriorates [6]. The pervasiveness of this phenomenon has led to the commercial development of acid detection strips (AD-Strips, Image Permanence Institute) which act as a colour indicator for the presence of acids around an object and are now a standard tool within heritage science. However, the AD-Strips are broadspectrum detectors that respond to all strong acids including those due to external pollutants, so the context of their use needs to be considered. They also lack the ability to accurately quantify the level of acid exposure; however, a published calibration by Hackney [7] using a colorimeter has improved their interpretation. 
The use of solid phase microextraction gas chromatography-mass spectrometry (SPME-GC/MS) has been proposed as a more rigorous technique to measure and identify the VOCs emitted from polymer artworks [8]. The technique's ability to harvest a large variety of VOCs has shown its potential to track both deterioration markers and identification markers from polymer artworks [9-12].Furthermore, the technique has also been used to characterise other materials within heritage environments such as wax [13], paper [14-17] and Asian lacquers [20].

However, the main unknown regarding SPME-GC/MS is its performance in an open museum environment. Previous researchers have carried out their analysis in a laboratory context, often using closed vials or Tedlar bags [8]. The use of this preconcentration and enclosure method hinders the analysis of larger objects and also precludes examination of objects in-situ in a heritage setting. Of the few studies to perform open analysis, most were single measurements from entire rooms rather than repeated analysis of single objects $[9,18,19]$. As such, there is limited information about the performance of SPME-GC/MS in open heritage environments. 
Research Questions

The work presented here follows that of [12] and expands on its evaluation of the collected data with the aim to answer a number of research questions related to the performance of SPME in an open \& complex museum environment. The key details which needed greater understanding are -

- What effect do large exposure times have on the resulting VOC profiles from objects housed in heritage environments such as museums?

- Does competition on the SPME fibre play a significant role in resulting VOC profiles at these exposure times?

- How does a complex background effect the interpretation of object VOC profiles?

- How do the above constraints effect our ability to closely monitor an object in-situ, and what implications do they have in relation to defining concentration levels experienced by the object. 


\section{Materials \& Methods:}

Analysis was conducted on the sculpture Construction in Space 'Two Cones' 1936 replica 1968 by the artist Naum Gabo (Object Number Tate T02143), which is now deemed un-displayable, and hence is stored and monitored at Tate Britain, London. The artwork is housed within a plastic packing crate, which is open at the top and has activated charcoal cloth surrounding its sides. Analysis was conducted between February and June 2017. Four 50/30 $\mu \mathrm{m}$ DVB/CAR/PDMS SPME fibres were placed around the object at points of interest (POI) which in consultation with conservators were deemed to be worthy of study. A fibre was placed at two locations showing high level of deterioration (Locations 2 \& 4) and one area which was close to the object yet away from these areas of high deterioration (Location 3). The fourth fibre was placed inside the object's storage crate but as far away from the object as possible (Location 5), thereby giving us information regarding the general environment inside the crate. Figure 1 shows the locations of the fibres around the object. A fifth fibre (Location 1, not shown on image) was also placed inside the room housing the object in order to give a background profile of VOCs in the vicinity of the object. Fibres were exposed for either 1 or 7 days at ambient temperature in the room at Tate Britain, London. 


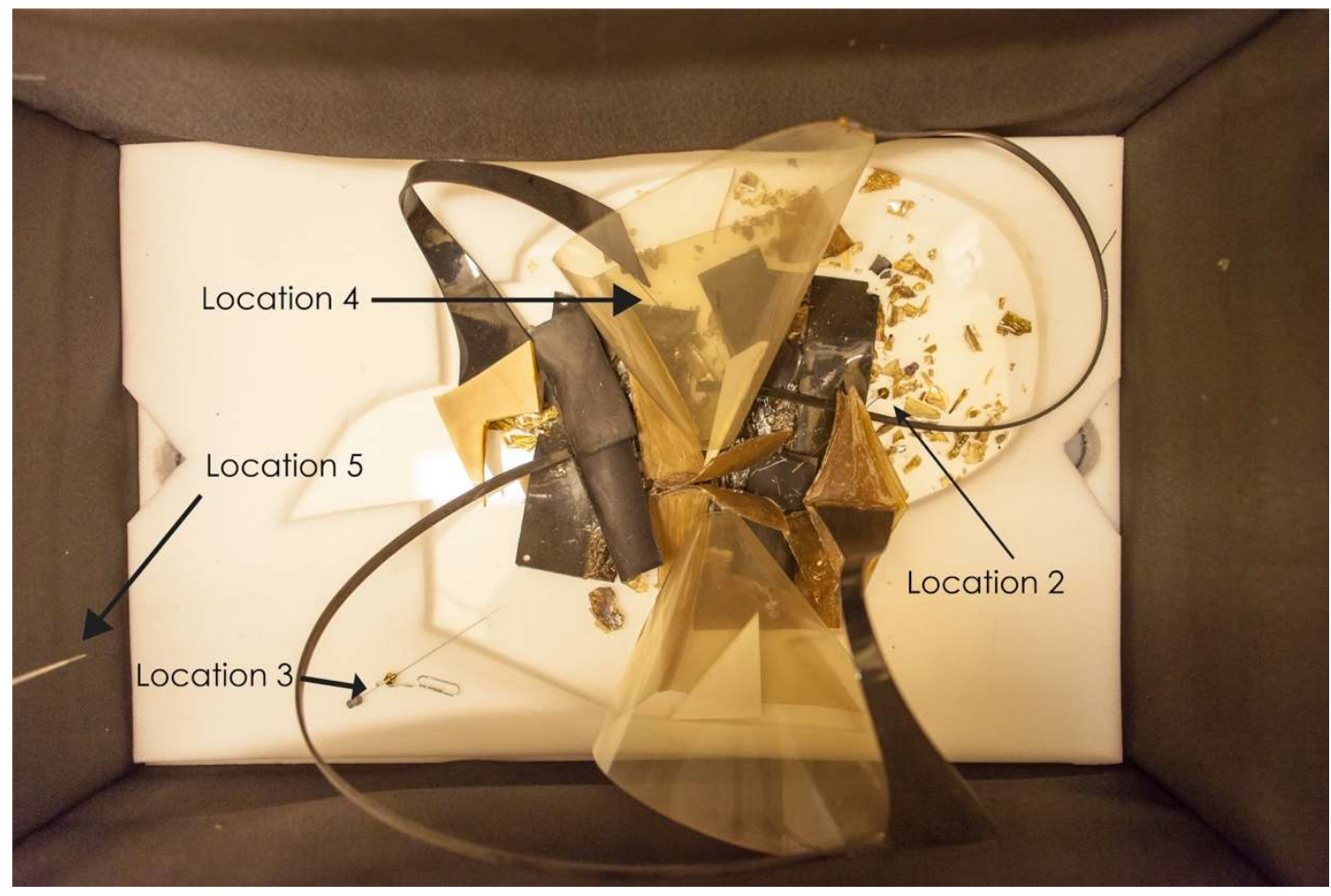

Figure 1 - Naum Gabo, Construction in Space 'Two Cones' 1936 replica 1968 in its storage crate, in a quarantine room for deteriorating CA-based artworks

Analysis of SPME fibres was conducted by manual injection into the port of a gas chromatograph (Perkin Elmer Clarus 500) connected to a mass spectrometer (Perkin Elmer Clarus 560D). A VOCOL column (Supelco, 20\% phenyl-80\%methylpolysiloxane) $60 \mathrm{~m}$ in length and $0.25 \mathrm{~mm}$ in diameter separated the VOCs. A heating ramp program was performed in which an initial temperature of $50^{\circ} \mathrm{C}$ was held for $5 \mathrm{~min}$, this was increased $10^{\circ} \mathrm{C} / \mathrm{min}$ to $100^{\circ} \mathrm{C}$ followed by increments of $5^{\circ} \mathrm{C} / \mathrm{min}$ to $200^{\circ} \mathrm{C}$ and $2^{\circ} \mathrm{C} / \mathrm{min}$ to $220^{\circ} \mathrm{C}$. The system was held at $220^{\circ} \mathrm{C}$ for 20 min giving a total heating time of $60 \mathrm{~min}$. The carrier gas was helium with a constant flow of $1 \mathrm{~cm}^{3} \mathrm{~min}^{-1}$. The injector temperature was $250^{\circ} \mathrm{C}$. The interface and source temperatures were $200^{\circ} \mathrm{C}$ and $180{ }^{\circ} \mathrm{C}$ respectively. Mass spectra were collected under electron ionization (El) mode at $70 \mathrm{eV}$ and recorded from $\mathrm{m} / \mathrm{z}=45-300$ over the same time period.

To remove any impact of variation in individual performance of the five SPME fibres, an external standard was used on each fibre directly after completing the analysis of the object's headspace. The peak areas from the object analysis were normalised to the peak area of ethylbenzene from a MISA Group 
17 Non-Halogen Organic Mix (Sigma Aldrich 48133 Supelco), that contained $2000 \mathrm{\mu g} / \mathrm{ml}$ each of benzene, ethylbenzene, styrene, tolvene and ortho-, meta- and para-xylene in methanol, diluted $1 / 10$ in methanol. The SPME fibre was exposed to the standard before being analysed in the GC/MS. In analysing the standard, a ramped temperature program was followed. The initial temperature of $35^{\circ} \mathrm{C}$ was held for $5 \mathrm{~min}$ then increased $10^{\circ} \mathrm{C} / \mathrm{min}$ to 200 ${ }^{\circ} \mathrm{C}$ with a total time of 31.5 minutes. A solvent delay of 2 min was used. Mass spectra were collected under electron ionization (EI) mode at $70 \mathrm{eV}$ and recorded from $\mathrm{m} / \mathrm{z}=45-300$.

Analysis of the resulting data was processed via a combination of OpenChrom \& \& Matlab $\&$ scripts which were written by the lead author of this paper. 


\section{Results \& Discussion:}

Initial findings -

Solid-phase microextraction (SPME) was typically able to identify the top 15 compounds from each POI and highlights the complex nature of both the object's immediate surroundings and the background environment it is housed in. Details on VOC type and localized relative proportions have previously been published [12]. However, in summary, we have chosen to focus our analysis on four compounds that were common to all analysis runs and are significant in the context of the object's composition. They are:

- acetic acid - which is both a deterioration and an identification marker for CA $[6,20]$

- diethyl \& dimethyl phthalate - which were both common plasticisers for CA [21]

- phenol - which may be a degradation product of the plasticiser triphenyl phosphate [22,23] 
Table 1: Retention time, observed $\mathrm{m} / \mathrm{z}$ values and an example value of the NIST $\mathbf{R}$ Match (taken from the 1-Day Set 3 Fib 2 sample) used in the identification of VOCs during the analysis.

\begin{tabular}{|l|c|c|c|}
\hline \multicolumn{1}{|c|}{ Compound } & $\begin{array}{c}\text { Retention } \\
\text { Time } \\
\text { (mins) }\end{array}$ & Observed m/z values & $\begin{array}{c}\text { NIST R } \\
\text { Match } \\
\text { value }\end{array}$ \\
\hline Acetic Acid & 10.82 & 59.5360 .5545 .51 & 988 \\
Phenol & 25.60 & 93.6965 .5964 .57 & 975 \\
Dimethyl Phthalate & 46.33 & 162.9176 .6175 .59 & 967 \\
Diethyl Phthalate & 54.83 & 148.89177 .06149 .91 & 958 \\
\hline
\end{tabular}

A central aim of our research was to study the impact of exposure time on the resulting VOC profiles, as a desideratum for any monitoring program is its ability to be undertaken in a timely fashion. Having consulted with conservators and based on the sensitivity of SPME fibres an exposure time of 1 day (24 hours) was deemed to be preferred while the 7-Day time frame was chosen as the longest convenient length. Our analysis showed that for an object displaying severe degradation like T02143 a 1-Day exposure was capable of resolving both identification and deterioration markers for CA as well as differentiating the object from its background (Figure 2). As discussed in [12] the 1-Day analysis led to the identification of VOC hotspots on the object. We showed that the ratio of phenol to acetic acid was not the same at each location, with the relative level of phenol at one location being significantly higher than the other.

This is an interesting result as it shows that despite the difference in volatility between the different compounds and the relatively high volatility of acetic acid there is clear evidence of localised effects on the object. At these

\footnotetext{
${ }^{1}$ An R-Match (or Reverse Match) is a match calculated by ignoring any peak(s) present in the sample mass spectrum that is not present in the library spectrum. It is a useful tool when comparing spectra which may have complex backgrounds or may have co-eluting compounds.
} 
distances (circa 300-500 mm between each POI) and timescales the diffusion of higher volatiles is limited and correspondingly does not result in a homogenised local value for the different compounds. The causes of this are likely partly due to different decay reactions (as discussed below), and a combination of differences in diffusion coefficients and air currents whose calculations are outside the remit of this study.

While both phenomena were present for both exposure times, they were less pronounced during the 7-Day analysis. This is a significant contribution to the understanding of the behaviour of the object within a heritage context. The presence of hot spots indicates that the charcoal cloth and open but unforced top ventilation of the object are not having the desired effect of mitigating the risks posed by exposure to these VOCs as discussed by Curran et al [10]. Furthermore, the discovery of different VOC ratios at different locations leads to the conclusion that two different decay mechanisms, the deacetylation of cellulose acetate and the decay of triphenyl phosphate to phenol, are occurring at the same time on a single object. This could potentially affect the way the object is managed and stored in the future. 

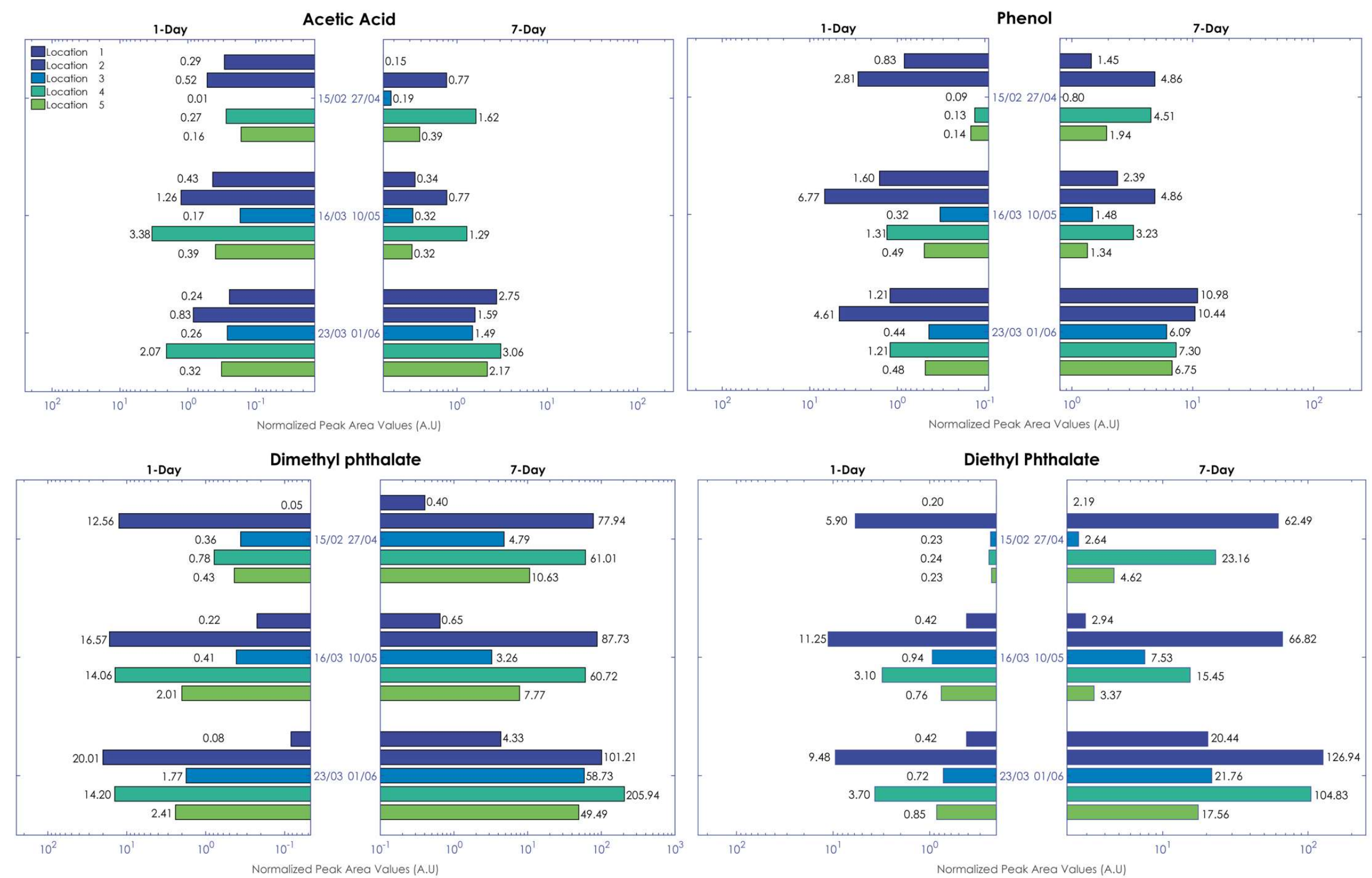

Figure 2: Normalized peak areas for our four target VOCs over the course of both 1-Day and 7-Day exposure. Values overlaid are unitless. Dates 
in middle refer to the day of analysis for each set of five analysis locations. Please note the log scale. This is a graphical presentation of the data found in Table 1 of [12] 
Repeatability -

While qualitive analysis of the data was straight forward, a more rigorous examination of the data highlighted clear differences between the exposure periods and between monitoring in an open museum environment versus a closed (lab-based) set-up. Our analysis has shown that an exposure time of 7 days led to a lower relative standard deviation (\%RSD) across all locations than that from an exposure of 1-Day (Figure 3).

\section{$\%$ RSD for 4 VOC from T02143 CA Sculpture}

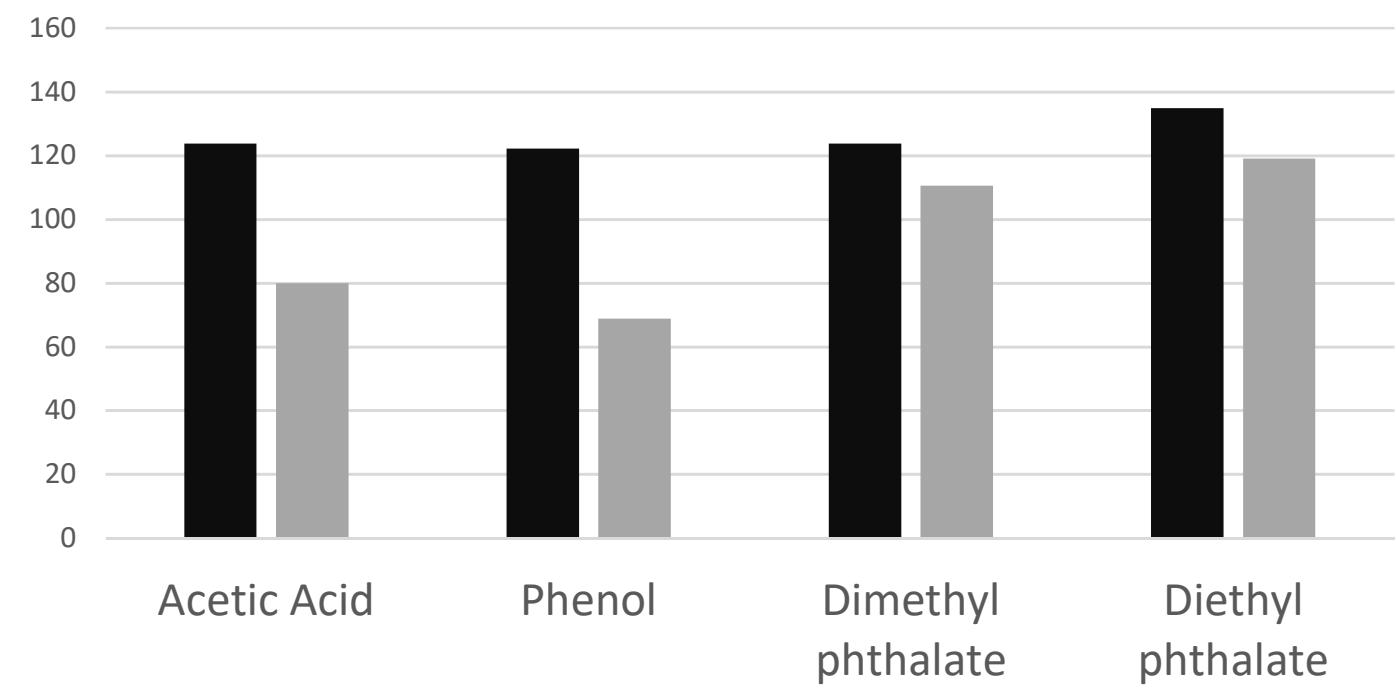

1-Day Exposure 7-Day Exposure

Figure 3 shows the \%RSD calculated from all data for each of the four VOCs over their respective time periods.

In each instance, the \%RSD of specific VOCs during the 1-Day analysis was higher than that of the 7-Day. The lower \%RSD of the 7-Day analysis would indicate that the fibres at each location are closer to reaching equilibrium than for the 1-Day analysis, although it should be noted that the \%RSD for the 7-Day analysis are all high.

In the shorter timeframe, those VOCs whose affinity for the fibre is greatest are absorbed first - giving us a snapshot of the conditions at that moment in time at that location [24]. The longer timeframe, which allows for equilibrium to be reached, results in a homogenized VOC profile where the abundance of the four major VOCs is not as different between each location. This is likely due to 
competition for places on the fibre being more influential, giving a more consistent picture of relative concentrations.

Less significant relative differences between each location at the 7-Day timeframe inhibits the detection of areas of interest, as shown by the lower differences in phenol and acetic acid ratios found by Kearney et al [12] after 7-Days.

If the data is viewed from an individual $\mathrm{PO}$ perspective, we see a reversal in the \%RSD results. In most cases, 1-Day spot analysis had a lower \%RSD at each position (Fig 3). One notable exception is at location 4 which has higher \%RSD for acetic acid and phenol. This location saw the greatest abundance of these two VOCs and as the time period was short, the amount the fibre at these locations are exposed to is governed by any external influencers. One of these is likely to be air movement due to disturbance of the case when performing the analysis combined with ambient air movement. A disturbance in the air surrounding the location prior to the analysis will lead to a deviation which in turn leads to a higher \%RSD. Furthermore, at the longer timeframe, the higher \%RSD observed is likely due to a combination of higher effects from temperature (which will be discussed later), relative humidity and air movement variability combined with the competition and matrix effect which were discussed earlier.

Additionally, the larger \%RSD seen for the 7-Day analysis is due in part to the final analysis set which was significantly different than the two previous sets. As will be discussed later, the likely main cause of this difference is likely a change in average temperature during the analysis. The implication of these findings is that while theoretically the analysis performed at the 7-Day timeframe produces the more consistent dataset of the relative concentration along with a more repeatable analysis between VOCs measured at all locations, in a real-world heritage environment it can be the most prone to external influences unless the monitoring is taking place in a tightly-controlled environment, and does not always provide the clarity needed to determine VOC hot spots around the object. 

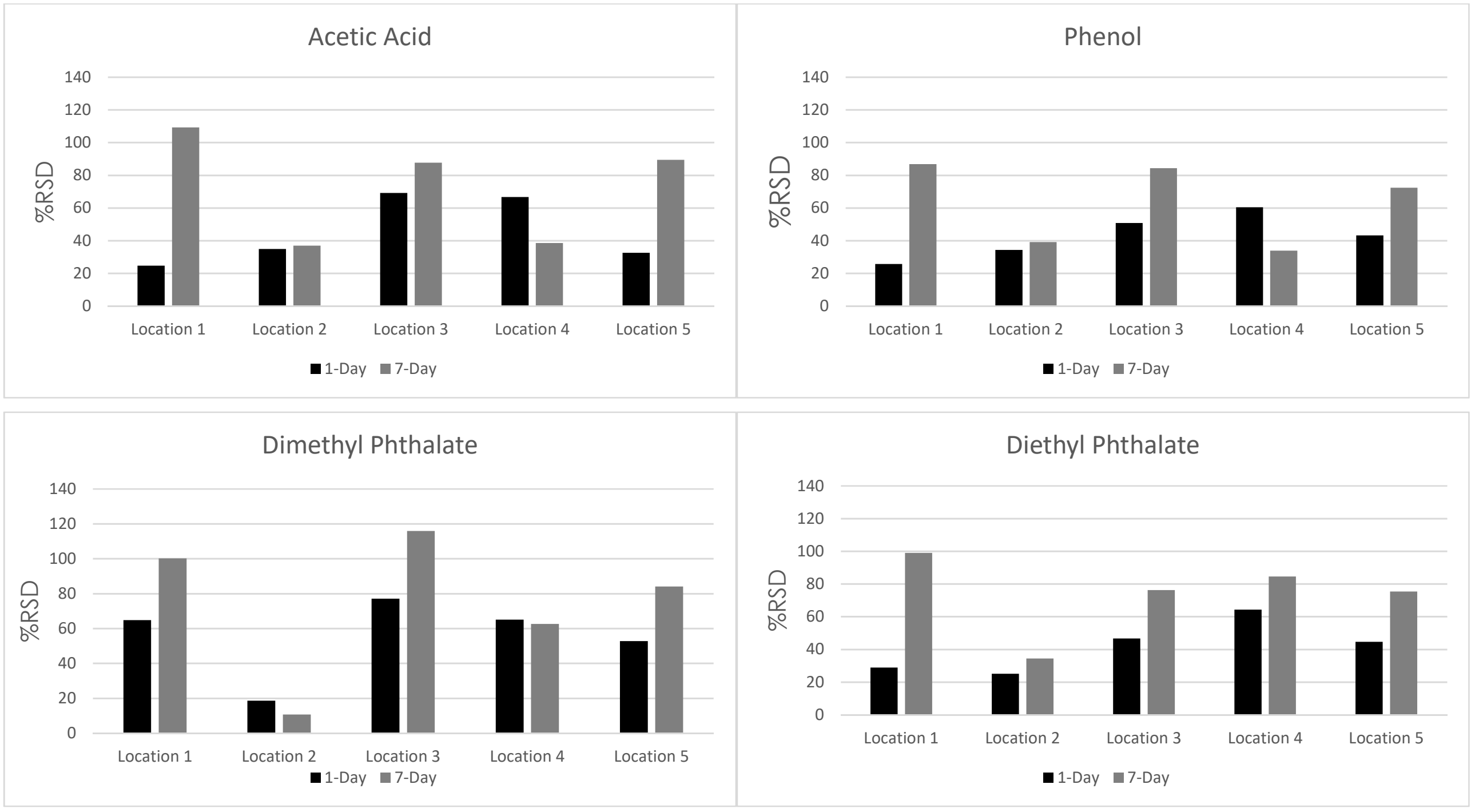

Figure 4 Shows the \%RSD at each location for our four target VOCs during 1-Day and 7-Day analysis. The results from 1-Day analysis are generally lower showing better repeatability during the 1-Day analysis. 
It is worth commenting on the high values of RSD. As can be seen from both Figure 3 \& 4, long-term SPME analysis within open environments leads to very high \%RSD results. The lowest \%RSD for a specific VOC, found around the object, was 68.7 \% (Phenol, 7 Day analysis) while the highest was $134.9 \%$ (Diethyl phthalate, 1 Day analysis). The POI with the lowest RSD, of $10.7 \%$, was found for dimethyl phthalate at location 2 during the 7-Day analysis, while the highest, at $115.9 \%$, was found at location 3 for the same VOC.

The resulting \%RSD do not match those previously reported in the literature where the analysis is carried out in a closed lab-based system [15,25-29] Typically, with these studies, the resulting \%RSD was less than $10 \%$. Furthermore, our unpublished internal examination of SPME analysis of polymer samples, utilising a closed system via a $20 \mathrm{ml}$ glass vial, yielded \%RSDs of between 5-15 \%. This is comparable to those found in the above literature. It is clear that the high \%RSD is a feature of open museum-based analysis and not an issue with our SPME fibres or GC/MS.

The implications of these results are significant for both qualitative and quantitative interpretations of the data, and the implementation of SPME for open environmental monitoring. In the first instance, it can be said that a 1Day exposure to this type of atmosphere is sufficient to capture relevant information regarding $\mathrm{VOC}$ composition of the object and potential areas of higher accumulation. However, care should be taken when discussing overall concentrations. This idea is in concurrence with Pörschmann et al [30] who noted that "the commonly used term 'concentration' in SPME analysis should be replaced by the more appropriate term "activity'". With regards to our highly decayed sample object, it is likely that equilibrium was not achieved after a period of 1 day. Therefore, it is not prudent to translate the result to a concentration, via a calibration curve, achieved under laboratory conditions at equilibrium.

Figure 2 also highlights the difficulty in monitoring an artwork over a period of several months. The difference in peak areas between the first and last set of 
the 7-Day analysis, which spanned approximately six weeks, is over double, almost triple for some VOC location combinations. While direct comparisons between 1-Day and 7-Day analysis is not preferable, the difference in resulting peak areas between 1-Day Set 1 and 7-Day Set 3 underscores the combined effects of exposure length, matrix, and fibre competition effects, and the effects of the uncontrolled environmental conditions during monitoring.

Role of Temperature -

The quarantine room which housed the object during monitoring was not environmentally controlled. The indoor temperature was therefore significantly affected by the outdoor temperature. 
Table 2: Shows the environmental conditions outside Tate Britain during the analysis. The room housing the object closely followed the outside environment. All temperature values are in ${ }^{\circ} \mathrm{C}$.

\begin{tabular}{|c|c|c|c|}
\hline 1-Day & $\begin{array}{l}\text { Average } \\
\text { Temp }\end{array}$ & Min Temp & Max Temp \\
\hline Set 1 & 8.4 & 4.6 & 13.6 \\
\hline Set 2 & 13.4 & 8.4 & 20.1 \\
\hline Set 3 & 10.1 & 5.6 & 14.3 \\
\hline 7-Day & $\begin{array}{l}\text { Average } \\
\text { Temp }\end{array}$ & Min Temp & Max Temp \\
\hline Set 1 & 11.5 & 3.1 & 21.6 \\
\hline Set 2 & 13.0 & 8.3 & 25.0 \\
\hline Set 3 & 22.2 & 14.2 & 31.3 \\
\hline
\end{tabular}

By combining the information gained from Table 2 and Figure 2 we observe that most VOC/location combinations follow the trend that a higher temperature leads to higher peak areas. For example, the peak area of phenol at location 2 is higher during 1-Day set 2 than 1-Day set 3, as is the average outdoor temperature during each analysis period. For 7-Day analysis the peak area is unchanged between set 1 and set 2 while the temperature difference between these two periods was only approx. 1.5 $5^{\circ} \mathrm{C}$. However, there is an almost $10^{\circ} \mathrm{C}$ increase in the average outdoor temperature during the period of analysis for set 3 which recorded over double the peak area at that location. Few papers have investigated the effect of temperature on SPME performance, while those that have focused on fibres that have been immersed into the sample rather than from the headspace $[31,32]$. Where the effects of temperature have been discussed with relation to the headspace [33] the researchers have used a CAR/PDMS fibre, which will behave differently to our DVB/CAR/PDMS. However, it is clear from the literature that increased temperature leads to increased emission of VOCs from the object 
resulting in an uptake of low molecular weight compounds, a phenomenon that we observe here.

Coupled with this phenomenon are the physical principles governing the uptake of compounds onto the fibre. Souza and Silva and Pawliszyn [28,34] both note that the distribution constant is temperature dependant and that raising the temperature will decrease this constant. The consequence of this is a lowering of the amount of sample extracted at equilibrium. The combined influence that temperature has on the resulting chromatogram again highlights the difficult nature of long-term uncontrolled open environment monitoring via SPME and has direct implications on the explicit statement of concentrations surrounding the object.

Matrix Effects -

In addition to this are the effects of competition for places on the fibre due to a combination of a long extraction time (even at 1-Day) and fibre coating choice. As discussed by Shirey in [34] "Because of limited capacity, analytes tend to compete more for the available sites [on the fibre]". If this occurs, then the "response for the displaced analyte will decrease and the analyte doing the displacement will increase". Unfortunately, it would be difficult to quantify this effect given our analysis conditions, yet it again highlights the dangers of placing a definitive value for concentration of VOCs from the results obtained.

\section{Background -}

Contaminations from the background affected the interpretation of the object's VOC profile. Limonene was sometimes found over the course of our analysis period in both background and sample profiles. This compound has been found previously in heritage environments and is likely due to cleaning products [35]. As discussed previously compounds which have a high affinity for the fibre will dislodge those with less affinity thereby lowering the perceived amount present. The addition of limonene would not only dislodge some pertinent VOCs but also cause confusion in reading the VOC profile of the object. 
As discussed previously [12] there was a clear difference between the background VOC profile and those profiles from areas of high decay. However, difficulties arose in interpreting the profiles from locations inside the object's storage crate which were not directly beside the object. One could assume that by placing a SPME fibre inside the storage crate of an object that one would see a profile from that object. Our findings show that this is not strictly the case and the exact location of the fibre in relation to the object is of vital importance.

A post-hoc Tukey analysis, following ANOVA analysis, revealed that locations 1 (background) and 5 (far from object while still within its storage crate) were similar to each other while location 2 (high decay area) was statistically different to the other two. Through examination of each individual compound we found that acetic acid was the only VOC which was not statistically different between locations (Figure 5). In essence, we gain almost the same level of information regarding the condition of object by placing a fibre 3 metres away from it as we do placing one 0.5 meters away within its storage crate. This information has major implications for future monitoring programs. On the one hand, it is quite easily to get reliable information about the type of VOCs surrounding an object (e.g I.D markers, decay compounds, additives) via SPME as a non-invasive \& non-destructive methodology. However, placing the SPME fibre some distance away from the object impacts the level of specificity as to which area of the object, or indeed if it is the object itself, that is emitting particular VOCs. Therefore, the initial question in any monitoring program must be to what level of confidence does one wish to be able to attribute specific VOCs to a specific object. 


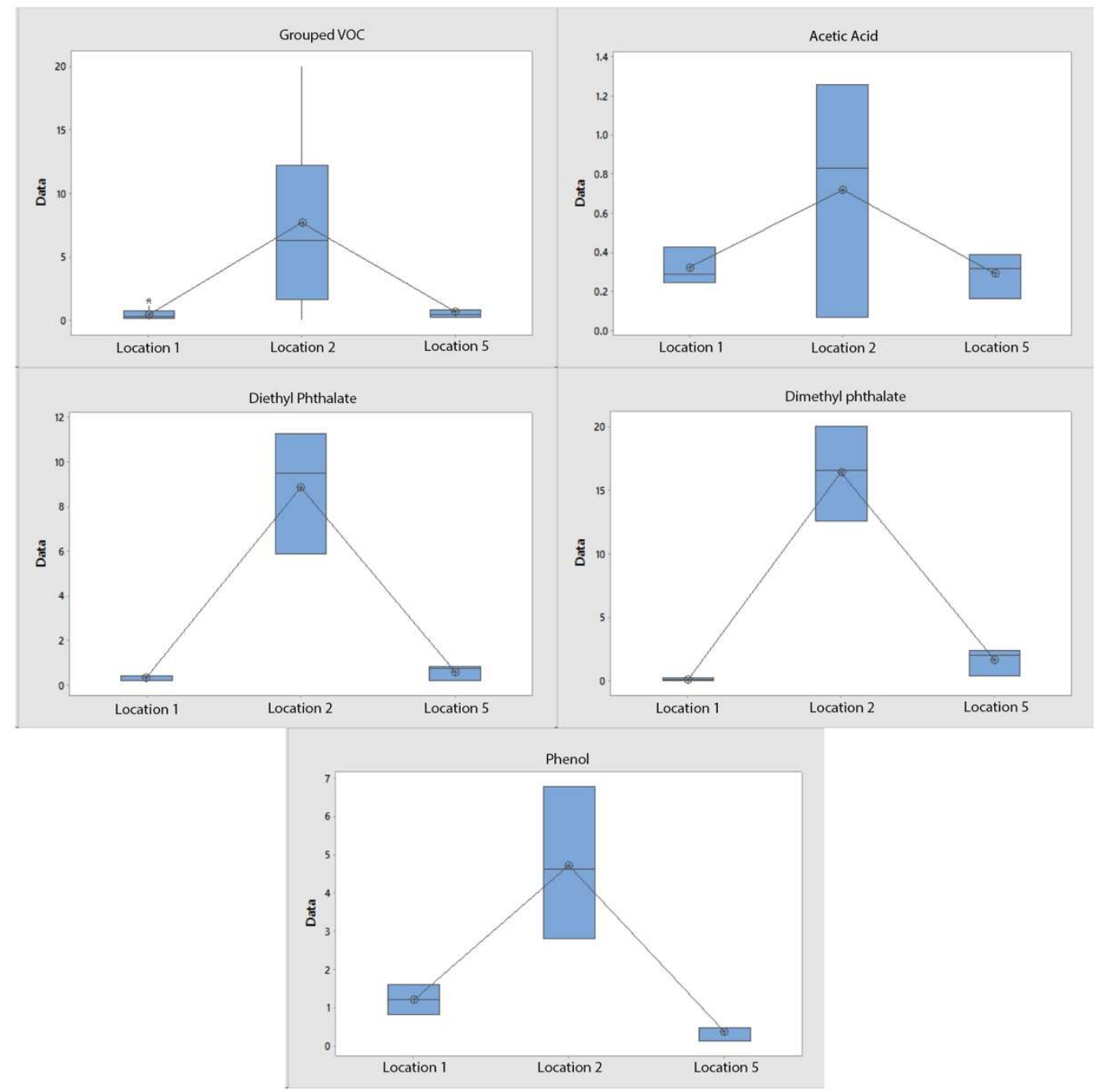

Figure 5 - Boxplots results created in Minitab 17, of grouped and individual VOCs showing the difference between locations 1, 2, and 5. In all cases, except for acetic acid there was a clear difference between locations 1 (background) \& 5 (away from the object), and location 2 (high decay area). 


\section{Conclusion}

Our analysis of the performance of SPME GC/MS within complex museum environments has shown that while one-off qualitative results are easily obtainable, difficulties arise when systematic monitoring over longer time periods is attempted.

Our results show that -

- Fibre placement, with relation to the analysis object, is key to determining if VOCs present in the resulting chromatogram are being emitted by that specific object or simply present in its surrounding background environment.

- While a 7-Day fibre exposure period provides the most technically accurate picture of VOCs surrounding the object, it also is the most vulnerable to external influences which can greatly affect the resulting VOC profile.

- A fibre exposed to the object for 1-Day offers the best repeatability over repeated long-term analysis, however, this comes at the cost of the ability to accurately determine concentrations.

- Given the long duration of exposure, even at 1-Day, it is reasonable to assume that competition for places on the fibre is occurring. This would result in VOCs with higher affinity to the fibre taking preference over those with lower affinity. Furthermore, it would also result in VOCs from the surrounding background contaminating the VOC profile from the objects, such as when limonene from cleaning products is found.

- The effects of temperature have a dramatic effect on the resulting VOC profile - this is due to a combination of chemical and physical factors. Increasing temperature increases the amount of VOCs present while at the same time lowering the partition coefficient of the SPME fibre which lowers the mount of analyte it is able to hold. This is an area of active research in our group.

\section{Funding -}


This project has received funding from the European Union's Horizon 2020 research and innovation programme (H2020 European Research Council) under grant agreement number 646063 and also this work was supported by Engineering and Physical Sciences Research Council: [grant number EP/L016036/1].

\section{Reference -}

[1] Y. Shashoua, Conservation of Plastics 1st Edition, Routledge, 2008.

[2] J.Paul Getty Trust, Conservation Perspectives: Conservation of Plastics, 2014.

[3] M. Strlič, K. Curran, Special issue "polymers in Art and History" - Editorial, Polym. Degrad. Stab. 107 (2014) 189-190.

doi:10.1016/j.polymdegradstab.2014.07.001.

[4] J.I.M. Williams, The role of science in the management of the UK' $s$ heritage, Heritage. (2009) 1-40.

[5] K. Curran, M. Strlic, Polymers and volatiles: Using VOC analysis for the conservation of plastic and rubber objects, Stud. Conserv. 0 (2014) 114. doi:10.1179/2047058413Y.0000000125.

[6] N.S. Allen, M. Edge, J.H. Appleyard, T.S. Jewitt, C.V. Horie, D. Francis, Degradation of historic cellulose triacetate cinematographic film: The vinegar syndrome, Polym. Degrad. Stab. 19 (1987) 379-387.

doi:10.1016/0141-3910(89)90067-0.

[7] S. Hackney, Colour measurement of acid-detector strips for the quantification of volatile organic acids in storage conditions, Stud. Conserv. 61 (2016) 55-69. doi:10.1080/00393630.2016.1140935.

[8] K. Curran, M. Underhill, L.T. Gibson, M. Strlic, The development of a SPME-GC/MS method for the analysis of VOC emissions from historic plastic and rubber materials, Microchem. J. (2016).

doi:10.1016/j.microc.2015.08.027.

[9] A. Lattuati-Derieux, C. Egasse, S. Thao-Heu, N. Balcar, G. Barabant, B. 
Lavédrine, What do plastics emit? HS-SPME-GC/MS analyses of new standard plastics and plastic objects in museum collections, J. Cult. Herit. 14 (2013) 238-247. doi:10.1016/j.culher.2012.06.005.

[10] K. Curran, A. Možir, M. Underhill, L.T. Gibson, T. Fearn, M. Strlič, Crossinfection effect of polymers of historic and heritage significance on the degradation of a cellulose reference test material, Polym. Degrad. Stab. 107 (2014) 294-306. doi:10.1016/j.polymdegradstab.2013.12.019.

[11] K. Curran, M. Underhill, J.G. $\varnothing$, T. Fearn, Classifying Degraded Modern Polymeric Museum Artefacts by Their Smell Angewandte, (2018) 74587462. doi:10.1002/ange.201712278.

[12] M. Kearney, I. Parkin, J.H. Townsend, M. Hidalgo, K. Curran, Characterisation of VOCs Surrounding Naum Gabo's Construction in Space 'Two Cones', (Tate) by in situ SPME GC-MS Monitoring, Stud. Conserv. 63 (2018) 369-371. doi:10.1080/00393630.2018.1486530.

[13] A. Lattuati-Derieux, S. Thao, J. Langlois, M. Regert, First results on headspace-solid phase microextraction-gas chromatography/mass spectrometry of volatile organic compounds emitted by wax objects in museums, J. Chromatogr. A. 1187 (2008) 239-249. doi:10.1016/j.chroma.2008.02.015.

[14] A. Lattuati-Derieux, S. Bonnassies-Termes, B. Lavédrine, Identification of volatile organic compounds emitted by a naturally aged book using solid-phase microextraction/gas chromatography/mass spectrometry, J. Chromatogr. A. 1026 (2004) 9-18. doi:10.1016/j.chroma.2003.11.069.

[15] A.J. Clark, J.L. Calvillo, M.S. Roosa, D.B. Green, J.A. Ganske, Degradation product emission from historic and modern books by headspace SPME/GC-MS: Evaluation of lipid oxidation and cellulose hydrolysis, Anal. Bioanal. Chem. 399 (2011) 3589-3600. doi:10.1007/s00216-011-4680-5.

[16] A. Lattuati-Derieux, O. Ramalho, C. Egasse, S. Thao-heu, A.-L. Dupont, Evaluation of Solid-Phase Microextraction On-Fiber Derivatization for the Analysis of Paper Degradation Compounds, EPresentation Serv. 12 (2015) 38-49. 
[17] J. La Nasa, M. Mattonai, F. Modugno, I. Degano, E. Ribechini, Comics' VOC-abulary: Study of the ageing of comic books in archival bags through VOCs profiling, Polym. Degrad. Stab. 161 (2019) 39-49. doi:10.1016/J.POLYMDEGRADSTAB.2019.01.001.

[18] B. Thiébaut, A. Lattuati-Derieux, M. Hocevar, L.B. Vilmont, Application of headspace SPME-GC-MS in characterisation of odorous volatile organic compounds emitted from magnetic tape coatings based on poly(urethane-ester) after natural and artificial ageing, Polym. Test. 26 (2007) 243-256. doi:10.1016/j.polymertesting.2006.10.006.

[19] C. Bembibre, M. Strlič, Smell of heritage: A framework for the identification, analysis and archival of historic odours, Herit. Sci. 5 (2017) 1-11. doi:10.1186/s40494-016-0114-1.

[20] B. Knight, Lack of evidence for an autocatalytic point in the degradation of cellulose acetate, Polym. Degrad. Stab. (2014). doi:10.1016/j.polymdegradstab.2013.12.002.

[21] G. Wypych, Plasticizers Use and Selection for Specific Polymers, Handb. Plast. (2004) 273-379. doi:10.1016/B978-1-895198-50-8.50013-8.

[22] Y. Shinagawa, M. Murayama, Y. Sakaino, Investigation of the Archival Stability of Cellulose Triacetate Film: The Effect of Additives to CTA Support, Postprints Polym. Conserv. (1992) 138-150.

[23] J. Tsang, O. Madden, M. Coughlin, A. Maiorana, J. Watson, N.C. Little, R.J. Speakman, Degradation of "Lumarith" cellulose acetate: examination and chemical analysis of a salesman's sample kit, Stud. Conserv. 54 (2009) 90-105.

[24] L. Tuduri, V. Desauziers, J.L. Fanlo, Potential of Solid-Phase Microextraction Fibers for the Analysis of Volatile Organic Compounds in Air, J. Chromatogr. Sci. 39 (2001) 521-529. doi:10.1093/chromsci/39.12.521.

[25] K. Curran, Sniffing out Decay: classifying degraded modern polymeric museum artefacts by their smell, (2017).

[26] P. Kusch, G. Knupp, Headspace-SPME-GC-MS identification of volatile 
organic compounds released from expanded polystyrene, J. Polym. Environ. 12 (2004) 83-87. doi:10.1023/B:JOOE.0000010053.20382.d7.

[27] K.D. Buchholz, J. Pawliszyn, Optimization of Solid-Phase Microextraction Conditions for Determination of Phenols, Anal. Chem. 66 (1994) 160167. doi:10.1021/ac00073a027.

[28] É.A. Souza Silva, G. Saboia, N.C. Jorge, C. Hoffmann, R.M. dos Santos Isaias, G.L.G. Soares, C.A. Zini, Development of a HS-SPME-GC/MS protocol assisted by chemometric tools to study herbivore-induced volatiles in Myrcia splendens, Talanta. 175 (2017) 9-20. doi:10.1016/j.talanta.2017.06.063.

[29] É.A. Souza-Silva, N. Reyes-Garcés, G.A. Gómez-Ríos, E. Boyaci, B. Bojko, J. Pawliszyn, A critical review of the state of the art of solid-phase microextraction of complex matrices III. Bioanalytical and clinical applications, TrAC - Trends Anal. Chem. 71 (2015) 249-264. doi:10.1016/j.trac.2015.04.017.

[30] J. Pörschmann, F.D. Kopinke, J. Pawliszyn, Solid-phase microextraction for determining the binding state of organic pollutants in contaminated water rich in humic organic matter, J. Chromatogr. A. 816 (1998) 159-167. doi:10.1016/S0021-9673(98)00525-1.

[31] R. Jiang, W. Lin, S. Wen, F. Zhu, T. Luan, G. Ouyang, Development of a full automation solid phase microextraction method for investigating the partition coefficient of organic pollutant in complex sample, J. Chromatogr. A. 1406 (2015) 27-33. doi:10.1016/j.chroma.2015.06.018.

[32] W. Lin, S. Wei, R. Jiang, F. Zhu, G. Ouyang, Calibration of the complex matrix effects on the sampling of polycyclic aromatic hydrocarbons in milk samples using solid phase microextraction, Anal. Chim. Acta. 933 (2016) 117-123. doi:10.1016/j.aca.2016.05.045.

[33] N.P. Brunton, D.A. Cronin, F.J. Monahan, The effects of temperature and pressure on the performance of Carboxen/PDMS fibres during solid phase microextraction (SPME) of headspace volatiles from cooked and raw turkey breast, Flavour Fragr. J. 16 (2001) 294-302. doi:10.1002/ffj.1000. 
[34] J. Pawliszyn, Handbook of Solid Phase Microextraction, Chemical Industry Press, 2009.

[35] L.T. Gibson, A. Ewland-Ahmen, B. Knight, V. Horie, G. Mitchell, C. Robertson, Measurement of volatile organic compounds emitted in libraries and archives: an inferential \rindicator of paper decay? Chem. Cent. J. 6 (2012) 1-22. doi:10.1186/1752-153X-6-42. 